\title{
Antibiogram of Pseudomonas species: an important tool to combat antibiotic resistance for patient safety in Gombe, Nigeria
}

\author{
${ }^{1}$ Manga, M. M., ${ }^{* 1}$ Ibrahim, M., ${ }^{2}$ Isaac, E. W., ${ }^{3}$ Hassan, M. D., ${ }^{3}$ Muhammad, G., \\ ${ }^{3}$ Hassan, U. M., and ${ }^{4}$ Yunusa-Kaltungo, $Z$. \\ ${ }^{1}$ Department of Medical Microbiology and Immunology, Gombe State University/ \\ Federal Teaching Hospital, Gombe, Nigeria \\ ${ }^{2}$ Infectious Diseases Unit, Department of Paediatrics, Gombe State University/ \\ Federal Teaching Hospital, Gombe, Nigeria \\ ${ }^{3}$ Department of Medical Microbiology and Immunology, Federal Teaching Hospital, Gombe, Nigeria \\ ${ }^{4}$ Plastic Surgery Unit, Department of Surgery, Federal Teaching Hospital, Gombe, Nigeria \\ *Correspondence to: mohgembu@yahoo.com; +2348060232264
}

\begin{abstract}
:
Background: Pseudomonas species are responsible for different healthcare-associated infections and are inherently resistant to many commonly used antibiotics. Hospital antibiograms are either absent or not regularly available in most healthcare facilities in Nigeria. The objective of this study is to present the antibiogram of Pseudomonas isolates in Federal Teaching Hospital Gombe (FTHG) in order to guide antibiotic prescription for better patient safety in the hospital.

Methodology: The is a hospital-based cross-sectional study. A total of 4309 bacterial isolates were recovered from aerobic cultures of routine clinical specimens including urine, sputum, blood, swabs, aspirates, biopsies, seminal fluids and cerebrospinal fluids at the Medical Microbiology laboratory of the hospital between January and December 2019. Pseudomonas species were identified by colony morphology, Gram-reaction and conventional biochemical tests. Antibiotic susceptibility testing was performed on each Pseudomonas isolate using the modified Kirby-Bauer disk diffusion method on Mueller-Hinton agar and results interpreted according to the guideline of the Clinical and Laboratory Standards Institute (CLSI). Data were analysed using the Statistical Package for Social Sciences (SPSS ${ }^{\mathrm{TM}}$ ) software version 23.0.

Results: Of the total 4309 bacterial isolates, $436(10.1 \%)$ Pseudomonas species were identified, with majority $(49.8 \%)$ from urine specimens. Antibiotic susceptibility test results revealed average susceptibility rates of $73.8 \%, 70.1 \%, 66.2 \%, 59.5 \%$, and $34.3 \%$ to ciprofloxacin, gentamicin, levofloxacin ceftazidime, and carbenicillin respectively. These rates fluctuate only slightly for each of the antibiotic during the 12 months period of survey.

Conclusion: Pseudomonas species were most sensitive to ciprofloxacin and gentamicin among the first line antibiotics in FTHG in 2019. Regular updates and presentation of hospital antibiogram especially for intrinsically resistant bacteria such as Pseudomonas involved in healthcare associated infections, is an important tool in combating antimicrobial resistance and ensuring patient safety.
\end{abstract}

Keywords: antibiogram, Pseudomonas, antimicrobial resistance, antimicrobial stewardship, patient safety

Received Jan 10, 2021; Revised Mar 7, 2021; Accepted Mar 8, 2021

Copyright 2021 AJCEM Open Access. This article is licensed and distributed under the terms of the Creative Commons Attrition 4.0 International License <a rel="license" href="http://creativecommons.org/licenses/by/4.0/", which permits unrestricted use, distribution and reproduction in any medium, provided credit is given to the original author(s) and the source. Editor-in-Chief: Prof. S. S. Taiwo

\section{Antibiogramme des espèces de Pseudomonas: un outil important pour lutter contre la résistance aux antibiotiques pour la sécurité des patients à Gombe, Nigéria}

\author{
${ }^{1}$ Manga, M. M., ${ }^{* 1}$ Ibrahim, M., ${ }^{2}$ Isaac, E. W., ${ }^{3}$ Hassan, M. D., ${ }^{3}$ Muhammad, G., \\ ${ }^{3}$ Hassan, U. M., et ${ }^{4}$ Yunusa-Kaltungo, $Z$. \\ ${ }^{1}$ Département de microbiologie médicale et d'immunologie, Université d'État de Gombe/ \\ Hôpital d'enseignement fédéral, Gombe, Nigéria
}


²Unité des maladies infectieuses, Département de pédiatrie, Université d'État de Gombe/ Hôpital d'enseignement fédéral, Gombe, Nigéria

${ }^{3}$ Département de microbiologie médicale et d'immunologie, Hôpital d'enseignement fédéral, Gombe, Nigéria

${ }^{4}$ Unité de chirurgie plastique, Département de chirurgie, Hôpital universitaire fédéral, Gombe, Nigéria *Correspondance à: mohgembu@yahoo.com; +2348060232264

\begin{abstract}
Abstrait:
Contexte: Les espèces de Pseudomonas sont responsables de différentes infections associées aux soins de santé et sont intrinsèquement résistantes à de nombreux antibiotiques couramment utilisés. Les antibiogrammes hospitaliers sont absents ou ne sont pas régulièrement disponibles dans la plupart des établissements de santé au Nigéria. L'objectif de cette étude est de présenter l'antibiogramme des isolats de Pseudomonas dans l'Hôpital Universitaire Fédéral de Gombe (FTHG) afin d'orienter la prescription d'antibiotiques pour une meilleure sécurité des patients à l'hôpital.

Méthodologie: Il s'agit d'une étude transversale en milieu hospitalier. Un total de 4309 isolats bactériens ont été récupérés à partir de cultures aérobies d'échantillons cliniques de routine, y compris l'urine, les crachats, le sang, les prélèvements, les aspirations, les biopsies, les fluides séminal et les fluides céphalo-rachidiens au laboratoire de microbiologie médicale de l'hôpital entre janvier et décembre 2019. Les espèces de Pseudomonas étaient identifié par la morphologie de la colonie, la réaction Gram et les tests biochimiques conventionnels. Des tests de sensibilité aux antibiotiques ont été réalisés sur chaque isolat de Pseudomonas en utilisant la méthode de diffusion sur disque Kirby-Bauer modifiée sur gélose Mueller-Hinton et les résultats ont été interprétés selon les directives du Clinical and Laboratory Standards Institute (CLSI). Les données ont été analysées à l'aide du logiciel Statistical Package for Social Sciences (SPSSTM) version 23.0.

Résultats: Sur les 4309 isolats bactériens au total, $436(10,1 \%)$ espèces de Pseudomonas ont été identifiées, la majorité $(49,8 \%)$ à partir d'échantillons d'urine. Les résultats des tests de sensibilité aux antibiotiques ont révélé des taux moyens de sensibilité respectivement de $73,8 \%, 70,1 \%, 66,2 \%, 59,5 \%$ et $34,3 \%$ à la ciprofloxacine, à la gentamicine, à la lévofloxacine ceftazidime et à la carbénicilline. Ces taux ne fluctuent que légèrement pour chacun des antibiotiques au cours de la période de 12 mois d'enquête.

Conclusion: les espèces de Pseudomonas étaient les plus sensibles à la ciprofloxacine et à la gentamicine parmi les antibiotiques de première intention dans le FTHG en 2019. Les mises à jour régulières et la présentation de l'antibiogramme hospitalier, en particulier pour les bactéries intrinsèquement résistantes telles que les Pseudomonas impliquées dans les infections associées aux soins, sont un outil important dans la lutte contre la résistance aux antimicrobiens et assurer la sécurité des patients.
\end{abstract}

Mots clés: antibiogramme, Pseudomonas, résistance aux antimicrobiens, gestion des antimicrobiens, sécurité des patients

\section{Introduction:}

Pseudomonas are non-fermentative oxidase-positive, motile, aerobic Gram-negative rods belonging to the family Pseudomonadaceae, with a large genome of approximately 6.3 million base pairs (Mbp), encoding 5567 genes(1). Pseudomonas commonly colonizes hospital environment, equipment, and have remained a prominent cause of healthcare-associated infections (HAIs) (2). They typically cause diseases in immunocompromised individuals but occasionally infects immunocompetent hosts, and are often associated with ventilator-associated pneumonia (VAP), central line-associated bloodstream infection (CLABSI), surgical site infection (SSI), respiratory infections in cystic fibrosis (CF) patients, and catheter-associated urinary tract infections (CAUTI) $(3,4)$.

Pseudomonas generally possesses several virulence factors including lipopolysaccharide, type IV pili, type III and VI secretion systems, alginate, exotoxin A, proteases, quorum sensing, generation of oxidants in the airways, formation of biofilm and pigments (1). Pseudomonas generally are intrinsically resistant to several antibiotics, and recently, more resistance from acquired sources is progressively increasing (5).
Antibiogram is a summary of the periodic susceptibility pattern of organisms isolated within a specific area which is regularly communicated to the hospital community to guide appropriate use of antimicrobials and empirical treatment of infections (6), while patient safety is a health care discipline that focuses more on preventing, controlling, and minimizing risks, harm, and errors in healthcare (7). Patient safety together with antimicrobial stewardship and infection prevention and control (IPC) constitutes the major pillars of an integrated approach to health systems strengthening (7).

Inappropriate use of antimicrobials is the main driving force in the development of resistance by microorganisms, and these resistant organisms pose significant threat to patient safety globally (8). Antibiogram classically promote optimal use of antimicrobials by encouraging a targeted approach,thereby reducing treatment-related cost and also minimizing or slowing the development of antimicrobial resistance leading to improved quality of life and patient safety (7).

Studies specifically on Pseudomonas antibiogram are few in this part of the country. Communication and dissemination of 
antiogram outcomes to health care workers, hospital community, and globally on regular basis, is also lacking. In this study, we present the FTHG 2019 Pseudomonas antibiogram, which is aimed at providing a guide for the empirical antibiotic prescribing practices among physicians to combat antimicrobial resistance for better patient safety.

\section{Materials and method:}

\section{Study setting and ethical approval}

This is a hospital-based cross-sectional study carried out in FTHG, a 457 beded tertiary hospital in north-eastern Nigeria. The hospital has a functional IPC programme and multidisciplinary patient safety team (MPST). Ethical approval for this study was obtained from the research and ethics committee of FTHG.

\section{Identification and antibiotic susceptibility of Pseudomonas specie isolates}

All Pseudomonas isolates recovered from clinical specimens (urine, sputum, blood, swabs, aspirates, biopsies, and seminal fluids) received and processed from at the Medical Microbiology laboratory of FTHG from January to December 2019, were included. Identification of Pseudomonas species was manually done using conventional methods including colonial morphology, Gram stain reaction, oxidase and motility tests.

Invitro susceptibility testing of the isolates to five commonest first-line antiPseudomonas antibiotics in our facility was performed by the modified Kirby-Bauer disk diffusion method on Mueller-Hinton agar using single antibiotic disks (ceftazidime $30 \mu \mathrm{g}$, gentamicin $10 \mu \mathrm{g}$, ciprofloxacin $5 \mu \mathrm{g}$, levofloxacin $5 \mu \mathrm{g}$ and carbenicillin $100 \mu \mathrm{g}$ ) (Oxoid, UK). The zone diameter of inhibition (measured in millimetres) for each isolate was interpreted as sensitive or resistant using the guidelines of the Clinical and Laboratory Standards Institute (CLSI) for Pseudomonas (9).

\section{Data analysis}

Data were analysed using the Statistical Package for Social Sciences (SPSS ${ }^{\mathrm{TM}}$ ) software version 23.0 .

\section{Results:}

Of the total 4309 bacterial isolates recovered from clinical specimens in 2019 at the Medical Microbiology laboratory of FTHG, Pseudomonas species were 436 (10.1\%), about half $(49.8 \%)$ of which were isolated from urine specimens while others were as shown in Table 1 . The monthly distribution and percentage antibiotic susceptibility of the Pseudomonas species are highlighted in Table 2.
The average sensitivity rates of Pseudomonas species against commonly used antibiotics in our facility were $73.8 \%$ (ciprofloxacin), 70.1\% (gentamicin), 66.2\% (levofloxacin), 59.5\% (ceftazidime) and 34\% (carbenicillin) (Fig 1).

Table 1: Distribution of Pseudomonas species isolated from different clinical specimens

\begin{tabular}{cc}
\hline Specimen type & No of Pseudomonas (\%) \\
\hline Urine & $217(49.8)$ \\
Swabs/ & $146(33.5)$ \\
aspirates/biopsies & \\
Sputum & $53(12.1)$ \\
Blood & $20(4.6)$ \\
Total & $\mathbf{4 3 6 ( 1 0 0 )}$ \\
\hline
\end{tabular}

\section{Discussion:}

Pseudomonas species are organisms with a remarkable propensity to develop resistance to a wide range of antibiotics more commonly in hospital settings. It has inherent resistance to many commonly used antibiotics thereby making it a frequent agent responsible for inappropriate empirical antibiotic therapy which is associated with increased healthcare burden. Poor prescribing practices have been identified as a major driver in the development of resistance against antibiotics with Pseudomonas being very prominent.

This study revealed a relatively high prevalence of Pseudomonas (10.1\%) among other bacterial isolates recovered from clinical specimens in Gombe, which is similar to $9.7 \%$ reported by Dash et al.,(10) in Peshawar, but higher than $5.1 \%$ reported in Nepal (11). This further highlights the significance of this pathogen and the importance of having an antibiogram to guide empiric antibiotic prescription especially given its inherent resistance to many commonly used drugs in the treatment of bacterial infections.

About half of the isolated Pseudomonas were from urine specimen which conforms to the findings by Shrestha et al., (11) and probably because urine is also the most common specimen received in our laboratory during the period Miscellaneous specimens such as swabs and aspirates usually from skin and soft tissue infections (SSTIs) and surgical site infection (SSIs) were very common sources of Pseudomonas isolates in our study, and similar to the findings of Dash et al., (12) in South Odisha, India.

The invitro susceptibility of Pseudomonas to ciprofloxacin was high at $73.8 \%$ average in this study, which was a similar 
Table 2: Monthly distribution of Pseudomonas species recovered from clinical specimens and their antibiotic susceptibility at Federal Teaching Hospital, Gombe, Nigeria

\begin{tabular}{|c|c|c|c|c|c|c|}
\hline \multirow{2}{*}{$\begin{array}{l}\text { Months in } \\
2019\end{array}$} & \multirow{2}{*}{$\begin{array}{c}\text { No of } \\
\text { Pseudomonas } \\
\text { isolates (\%) }\end{array}$} & \multicolumn{5}{|c|}{ No of Pseudomas isolates sensitive to the antibiotics (\%) } \\
\hline & & CIP & LEV & CAZ & $\mathbf{C N}$ & CAR \\
\hline January & $49(11.2)$ & $33(67.3)$ & $28(57.1)$ & $31(63.3)$ & $32(65.3)$ & $9(18.4)$ \\
\hline February & $24(5.5)$ & $16(66.7)$ & $14(58.3)$ & $14(58.3)$ & $16(66.7)$ & $12(50.0)$ \\
\hline March & $35(8.0)$ & $28(80.0)$ & $21(60.0)$ & $21(60.0)$ & $23(65.7)$ & $15(42.9)$ \\
\hline April & $37(8.5)$ & $30(81.1)$ & $22(59.5)$ & $22(59.5)$ & $26(70.3)$ & $13(35.1)$ \\
\hline May & $19(4.4)$ & $13(68.4)$ & $12(63.2)$ & $13(68.4)$ & $14(73.7)$ & $5(26.3)$ \\
\hline June & $40(9.2)$ & $28(70.0)$ & $29(72.5)$ & $28(70.0)$ & $30(75.0)$ & $16(40.0)$ \\
\hline July & $29(6.7)$ & $20(69.1)$ & $19(65.5)$ & $17(58.6)$ & $22(75.9)$ & $17(58.6)$ \\
\hline August & $40(9.2)$ & $30(75.0)$ & $32(80.0)$ & $25(62.5)$ & $26(65.0)$ & $17(42.5)$ \\
\hline September & $47(10.8)$ & 37 (78.7) & $32(68.1)$ & $28(59.6)$ & $37(78.7)$ & $13(27.7)$ \\
\hline October & $42(9.6)$ & $35(83.3)$ & $32(72.2)$ & $21(50.0)$ & $28(66.7)$ & $9(21.4)$ \\
\hline November & 51 (11.7) & $36(70.6)$ & $40(78.2)$ & $27(52.9)$ & $34(66.7)$ & $13(25.5)$ \\
\hline December & $23(5.2)$ & $18(78.3)$ & $14(61.0)$ & $12(52.2)$ & $18(78.3)$ & $11(49.0)$ \\
\hline Total & $436(100)$ & $\begin{array}{c}322 \\
(73.8)\end{array}$ & $\begin{array}{c}289 \\
(66.2)\end{array}$ & $\begin{array}{c}259 \\
(59.5)\end{array}$ & $\begin{array}{c}306 \\
(70.1)\end{array}$ & $150(34.3)$ \\
\hline
\end{tabular}

CIP = Ciprofloxacin, LEV = Levofloxacin, CAZ = Ceftazidime,$C N=$ Gentamicin, CAR = Carbenicilin

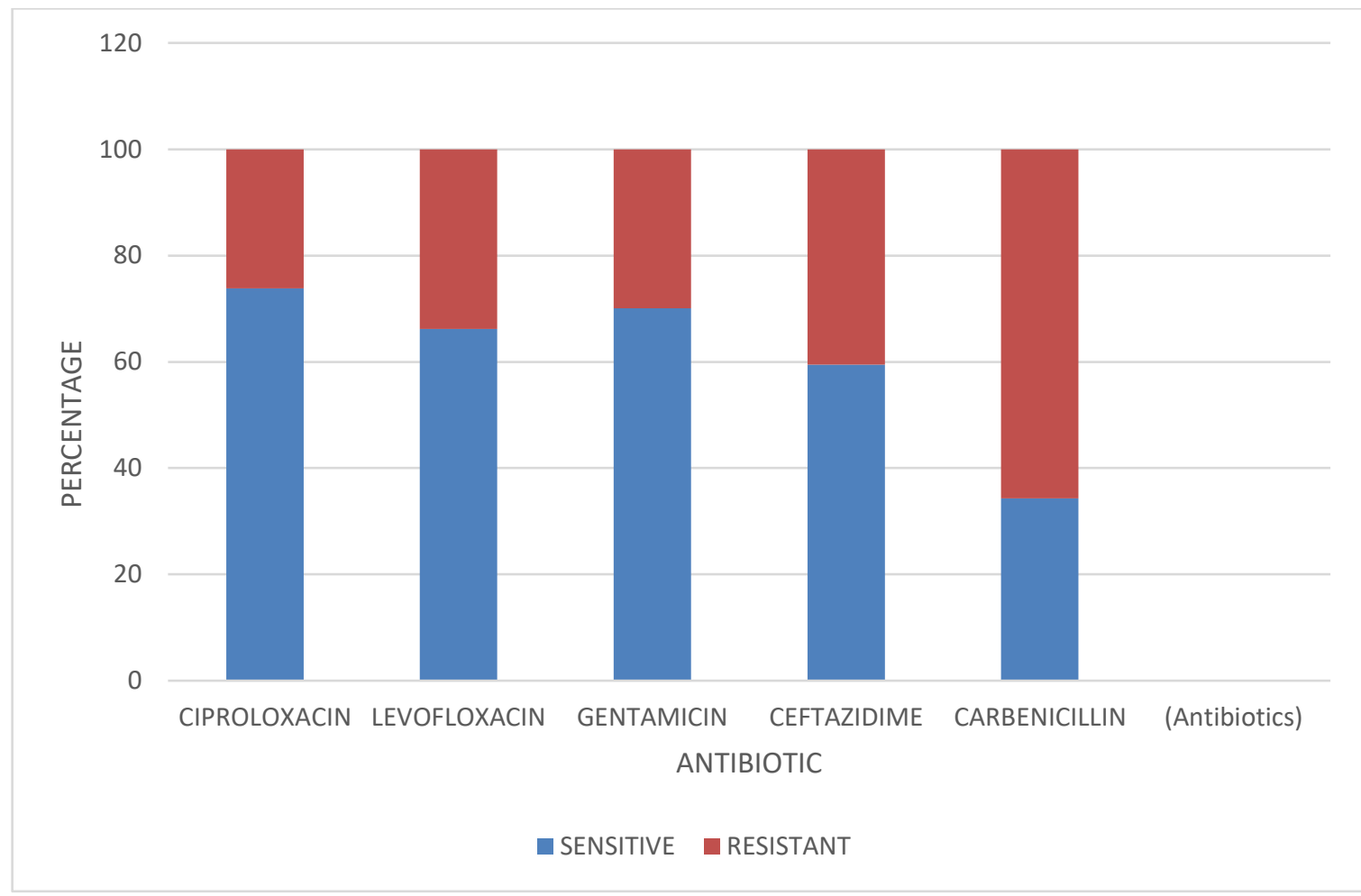

Fig 1: Average percentage sensitivity and resistance of Pseudomonas to first-line antimicrobials

pattern reported by Balogun et al., (13) in Maiduguri, which is in the same geographical region as Gombe in Nigeria. Geographical and social similarity, as well as prescribing habits and health indices between Gombe and Maiduguri, could play a role in this context. The susceptibility to gentamicin was also relatively high, similar to that reported by Shrestha et al.,(11). The $59.6 \%$ susceptibility rate to ceftazidime (a third generation cephalosporin) reported in this study is similar to the rate reported by Gill et al., (14) and Iregbu et al., (15). A study in Saudi-Arabia by Rashid et al., (16) reported $70.0 \%$ sensitivity of Pseudomonas to levofloxacin, which is similar to $66.2 \%$ reported by us, as against a higher resistance rate $36.1 \%$ reported by Dash et al.(12).

Carbenicillin, a carboxypenicillin used in the treatment of Pseudomonas infections, showed little invitro efficacy as only $34.3 \%$ of the Pseudomonas isolates were sensitive to it 
in our study, similar to a study conducted by Jazani et al., in Iran with 35\% sensitivity rate. This high resistance rate may be due to the increasing transfer of beta-lactamase genes between Pseudomonas species and members of the family Enterobacteriaceae (17).

The monthly susceptibility rates show very little variations of Pseudomonas isolates to each of the 5 commonly used anti-Pseudomonas antibiotics in our facility. These antibiogram results were discussed monthly and annually presented to the hospital community at the instance of the MPST, outlining the trend of infection, susceptibility, and resistant patterns of Pseudomonas species to guide and improve antibiotic prescribing practices.

\section{Conclusion:}

Antibiogram remains an important tool in combating AMR through improved prescribing practices at all levels of healthcare delivery. Pseudomonas are among the common clinically important bacterial isolates in Gombe and most commonly recovered from urine and swabs/aspirates associated with healthcare-associated urinary tract and skin/soft tissue infections. Among the first line antibiotics at FTHG in 2019, Pseudomonas were most sensitive to ciprofloxacin and least sensitive to carbenicillin.

\section{Acknowledgments:}

The authors acknowledge with thanks Gloria Micheal, Aishatu Julde, and S. Kwainranga of the Department of Medical Microbiology, FTHG, for their contributions.

\section{Conflict of interest:}

No conflict of interest is declared.

\section{Previous publication}

Oral presentation of this paper was made at the Virtual Conference of the Clinical Microbiology and Infectious Disease Society of Nigeria (CLIMIDSON) via Zoom on $26^{\text {th }}$ $27^{\text {th }}$ November 2020, and the abstract has been published in the conference program.

\section{References:}

1. Rocha, A. J., Barsottini, M. R. de O., Rocha, R. R., Laurindo, M. V., de Moraes, F. L. L., andda Rocha, S. L. Pseudomonas aeruginosa: Virulence Factors and Antibiotic Resistance Genes. Brazilian Arch Biol Technol. 2019; 62: e19180503.

2. Gómez-zorrilla, S., Camoez, M., Tubau, F., et al.
Prospective Observational Study of Prior Rectal Colonization Status as a Predictor for Subsequent Development of Pseudomonas aeruginosa Clinical Infections. Antimicrob Agents Chemother. 2015;59(9):5213-5219.

3. Molecolare, B., and Microbiologia, S. Treatment and control of severe infections caused by multiresistant Pseudomonas aeruginosa. Clin Microbiol Infect Suppl. 2005; 11 (4): 17-32. http://dx.doi.org/10.1111/j.1469- 0691.2005.01161.x

4. Cohen, R., Babushkin, F., Cohen, S., et al. A prospective survey of Pseudomonas aeruginosa colonization and infection in the intensive care unit. Antimicrob Resist Infect Control. 2017; 6(7). http://dx.doi.org/10.1186/s13756-0160167-7

5. Horcajada, J. P., Montero, M., Oliver, A., et al. Epidemiology and Treatment of MultidrugResistant and Extensively Drug-Resistant. Clin Microbiol Rev. 2019; 32 (4): 1-52.

6. Joshi, S. Hospital antibiogram: A necessity. Indian J Med Microbiol. 2010;28(4):277-280.

File, T. M., Srinivasan, A., and Bartlett, J. G. Antimicrobial stewardship: importance for patient and public health. Clin Infect Dis. 2014; 59 (Suppl 3): S93-S96.

8. Zarkadas, P., and Toska, A. Risk factors and attributable mortality of carbapenem- resistant Acinetobacter baumannii infections. HIth Sci J. 2014; 8 (1): 126-136.

9. Clinical Laboratory and Standards Institute (CLSI). Perfomance Standards for antimicrobial susceptibility testing; 28th ed. Wayne, Pennsylvania: Clinical and Laboratory Standards Institute; 2019.

10. Samad, A., Ahmed, T., Rahim, A., Khalil, A., and Ali, I. Antimicrobial susceptibility patterns of clinical isolates of Pseudomonas aeruginosa isolated from patients of respiratory tract infections in a Tertiary Care Hospital, Peshawar. Pak J Med Sci. 2017;33(3):670-674.

11. Shrestha, S., Amatya, R., and Adhikari, R. P. Prevalence and antibiogram of Pseudomonas aeruginosa isolated from clinical specimens in a Teaching Hospital, Kathmandu. Int J Infect Dis. 2016;45:115-116.

http://dx.doi.org/10.1016/j.ijid.2016.02.292

12. Dash, M., Padhi, S., Narasimham, M. V., and Pattnaik, S. Antimicrobial resistance pattern of Pseudomonas aeruginosa isolated from various clinical samples in a tertiary care hospital, South Odisha, India. Saudi] HIth Sci. 2020;3 (1):1519.

13. Okon, K., Agukwe, P. C., Oladosu, W., Balogun, S. T., and Uba, A. Resistance pattern of Pseudomonas aeruginosa isolated from clinical specimens in a Tertiary Hospital in Northeastern Nigeria. Internet J Microbiol. 2009; 8 (2). www.ispub.com

14. Gill, M. K., and Khanna, A. Antibiogram of Pseudomonas aeruginosa Isolated from Infected wounds. P Int J Med Microbiol Trop Dis. 2019; 5 (3): 163-165.

15. Hassan, T., Omer, S., Ali, S., and Mustafa, M. Antibiogram of Pseudomonas aeruginosa Isolates from Patients with Diabetic Septic Wounds Attending Two Public Hospitals in Khartoum, Sudan. Research Square (Preprint) DOI: $10.21203 /$ rs.3.rs-31745/v1

16. Rashid, A., Chowdhury, A., Rahman, S. H. Z., Begum, S. A., and Muazzam, N. Infections by Pseudomonas aeruginosa and Antibiotic Resistance Pattern of the Isolates from Dhaka Medical College Hospital. Bangladesh J Med Microbiol. 2007; 01 (02): 48-51.

17. Jazani, N. H., and Babazadeh, H. Evaluation of the Sensitivity of Pseudomonas aeruginosa. J Biol Sci. 2008; 8 (2): 486-489. 